\title{
International
} Journal of Trichology

\section{Hypotrichosis with Juvenile Macular Dystrophy}

Filipa Tavares Almeida, $\underline{\text { Rui Carneiro-Freitas }},{ }^{1}$ Regina Caldas, and Ana Paula Vieira

Department of Dermatovenereology, Hospital de Braga, Braga, Portugal

${ }^{1}$ Department of Ophtalmology, Hospital de Braga, Braga, Portugal

Address for correspondence: Dr. Filipa Tavares Almeida, Rua Humberto Delgado 555, Ermesinde, Porto, Portugal. E-mail: filipa.almeida6@hotmail.com

\section{Copyright : @ 2018 International Journal of Trichology}

This is an open access journal, and articles are distributed under the terms of the Creative Commons AttributionNonCommercial-ShareAlike 4.0 License, which allows others to remix, tweak, and build upon the work noncommercially, as long as appropriate credit is given and the new creations are licensed under the identical terms.

\section{Abstract}

Hypotrichosis with juvenile macular dystrophy is a rare autosomal recessive disease, characterized by hypotrichosis and progressive macular degeneration, leading to blindness in the first three decades of life. It is associated with mutations in the cadherin 3 gene, resulting in the abnormal expression of P-cadherin. We report a case of a 4-year-old female patient diagnosed with this genodermatosis.

Key words: Blindness, hypotrichosis with juvenile macular dystrophy, P-cadherin, trichoscopy

\section{INTRODUCTION}

Hypotrichosis with juvenile macular dystrophy (HJMD) is a rare autosomal recessive disease, characterized by hypotrichosis and progressive macular degeneration, leading to blindness in the first three decades of life.[1] It is associated with mutations in the cadherin 3 (CDH3) gene, resulting in the abnormal expression of P-cadherin.[2]

\section{CASE REPORT}

A 4-year-old female patient was referred to our department due to abnormally short scalp hair, that never had a haircut. Her growth and development were normal. Physical examination revealed short, sparse scalp hair, fine in texture, with low overall density [ㅍigure 1a]. The maximum hair length on the parietal scalp was $2 \mathrm{~cm}$. The hairs were easily and painlessly pulled from the scalp with gentle traction. Eyelashes, eyebrows, and body hair were normal. Clinical examination did not reveal any abnormalities of the skin, teeth, nails, and limbs. Trichoscopy showed short, thin, and vellus hairs and rare yellow dots [Figure $1 \mathrm{~b}]$. Optical and scanning electron microscopy examination revealed normal hair shafts and neither ruffled cuticles nor hockey stick-shaped bulbs were found.

Structural analysis of the hair shafts using X-ray spectroscopy showed bioelement values similar to those of normal controls. A systemic examination, serum and urine analysis, including vitamins and amino acids measurement and biotinidase activity, did not reveal other anomalies.

As we proceed with investigations, the girl complained about photophobia and was referred to Ophthalmology. At ophthalmological consultation, best-corrected visual acuity was $5 / 10$ in both eyes. Fundus examination revealed pigmentary alterations in the fovea bilaterally. Optical coherence tomography demonstrated irregularity of the photoreceptor layer and intraretinal cysts [iigure 2]. 
Clinical findings suggested the diagnosis of HJMD and a genetic study was performed. It revealed a c. 830delG homozygous mutation in the $\mathrm{CDH} 3$ gene, that is, responsible for the formation of a premature stop codon, leading to the synthesis of a truncated protein unable to fulfill its physiologic functions. Our clinical suspicious was supported, and the girl's parents were referred to genetic counseling. The absence of other anomalies, apart from hypotrichosis and retinal dystrophy, discarded ectodermal dysplasia, ectrodactyly, and macular dystrophy (EEM).

\section{DISCUSSION}

HJMDis a genodermatosis reported in approximately 50 cases worldwide and all share mutations in CDH3 on 16q21.[ㄹ] $\mathrm{CDH} 3$ is also responsible for another autosomal recessive disorder with hypotrichosis and progressive macular dystrophy: EEM.[4] CDH3 encodes P-cadherin, a calcium-dependent cell-cell adhesion molecule, that is strongly expressed in both the hair follicle and the retinal pigment epithelium. [5] Its deficiency may lead to abnormal hair and retinal pigment epithelial cell development by interfering in $\beta$-catenin system. As cadherins mediate cell-cell adhesion at the adherens junction, these symptoms can also result from weak or absence cell-cell contact within the upper hair matrix and the retinal pigment epithelial cells.[]

Symptom severity varies for each individual, but all share common features of retinal degeneration and short sparse scalp hair from birth, with limited growth throughout life.[]] Diagnosis is based on the combined occurrence of hypotrichosis with characteristic degenerative changes and pigmentary abnormalities of the fovea on fundoscopy. Complementary examinations such as light microscopy and scanning electron microscopy of the hair shafts can be normal, as seen in our patient, or reveal structural abnormalities, being pili torti one of the most frequent.[6] When performed, histopathologic examination of scalp biopsy shows mostly catagen hair follicles and an increased ratio of vellus hair follicles to terminal hair follicles. In fact, the most frequent histologic alteration in HJMD resembles chronic telogen effluvium, suggesting that the absence of functional P-cadherin interferes with normal hair cycle.[]]

The most severe complication of HJMD is visual deterioration that culminates in blindness. Despite the term juvenile macular dystrophy applied to this disease, most of the reported cases describe an earlier onset and a wider involvement of the retina, beyond the macula.[9]

To conclude, HJMD is a rare genetic disease, which makes it difficult to diagnose. It is important to maintain a high level of suspicion in cases of hypotrichosis, allowing the early diagnosis of this genodermatosis, to provide a multidisciplinary follow-up, especially by ophthalmology.

Given the advances in stem cell and genetic therapies for retinal diseases, reporting these cases is valuable to acknowledge phenotypic and genetic characteristics of this entity and to select patients for future treatments.[10]

\section{Declaration of patient consent}

The authors certify that they have obtained all appropriate patient consent forms. In the form the patient(s) has/have given his/her/their consent for his/her/their images and other clinical information to be reported in the journal. The patients understand that their names and initials will not be published and due efforts will be made to conceal their identity, but anonymity cannot be guaranteed.

\section{Financial support and sponsorship}

Nil.

\section{Conflicts of interest}

There are no conflicts of interest.

\section{Acknowledgments}

- The authors thank Juan Ferrando, MD, PhD (Associate Professor in the Department of Dermatology, Hospital Clínic and Barcelona University Medical School-Spain) for his helpful advices and review of the manuscript. We also thank his research group from Centros Científicos y Tecnológicos, 
Unidad de Microscopía Electrónica de Barrido, Barcelona (Spain), for assistance with hair shafts analysis using scanning electron microscopy and Energy Dispersive X-Ray Spectroscopy (EDS)

- The authors thank Dr. Rui Fernandes and Dr. Rossana Correia from Histology and Electron Microscopy/Instituto de Investigação e Inovação em Saúde, Universidade do Porto (Portugal) for assistance with hair shafts analysis using optical microscopy, transmission electron microscope (TEM) andEDS.

\section{REFERENCES}

1. Sequence variants in the $\mathrm{CDH} 3$ gene encoding P-cadherin underlying hypotrichosis with Ahmad F, Ali RH, Muhammad D, Nasir A, Umair M, Wakil SM, et al. Novel homozygous juvenile macular dystrophy in consanguineous families. Eur J Dermatol. 2016;26:610-2. [PubMed: 27456782]

2. Elfatoiki FZ, Cordoliani F, Pascal Regane P, Afforitit-Demoge A. Hypotrichosis with juvenile macular dystrophy: Portuguese case. Dermatol Online J. 2016;22:pii: 13030/qt0w28m8h4.

3. Vicente LP, Finzi S, Susanna R, Jr, Young TL. Hypotrichosis with juvenile macular dystrophy: A case report with molecular study. Arq Bras Oftalmol. 2017;80:49-51. [PubMed: 28380103]

4. Blanco-Kelly F, Rodrigues-Jacy da Silva L, Sanchez-Navarro I, Riveiro-Alvarez R, Lopez-Martinez MA, Corton M, et al. New CDH3 mutation in the first spanish case of hypotrichosis with juvenile macular dystrophy, a case report. BMC Med Genet. 2017;18:1. [PMCID: PMC5219735] [PubMed: 28061825]

5. Shimomura Y, Wajid M, Shapiro L, Christiano AM. P-cadherin is a p63 target gene with a crucial role in the developing human limb bud and hair follicle. Development. 2008;135:743-53. [PubMed: 18199584]

6. Indelman M, Bergman R, Lurie R, Richard G, Miller B, Petronius D, et al. Amissense mutation in $\mathrm{CDH} 3$, encoding P-cadherin, causes hypotrichosis with juvenile macular dystrophy. J Invest Dermatol. 2002;119:1210-3. [PubMed: 12445216]

7. Indelman M, Hamel CP, Bergman R, Nischal KK, Thompson D, Surget MO, et al. Phenotypic diversity and mutation spectrum in hypotrichosis with juvenile macular dystrophy. J Invest Dermatol. 2003;121:1217-20. [PubMed: 14708629]

8. Bergman R, Sapir M, Sprecher E. Histopathology of hypotrichosis with juvenile macular dystrophy. Am J Dermatopathol. 2004;26:205-9. [PubMed: 15166507]

9. Khan AO, Bolz HJ. Phenotypic observations in "hypotrichosis with juvenile macular dystrophy" (recessive CDH3 mutations) Ophthalmic Genet. 2016;37:301-6. [PubMed: 26885695]

10. Singh MS, Broadgate S, Mathur R, Holt R, Halford S, MacLaren RE, et al. Hypotrichosis and juvenile macular dystrophy caused by $\mathrm{CDH} 3$ mutation: A candidate disease for retinal gene therapy. Sci Rep.

2016;6:23674. [PMCID: PMC4860587] [PubMed: 27157923]

\section{Figures and Tables}




\section{Figure 1}

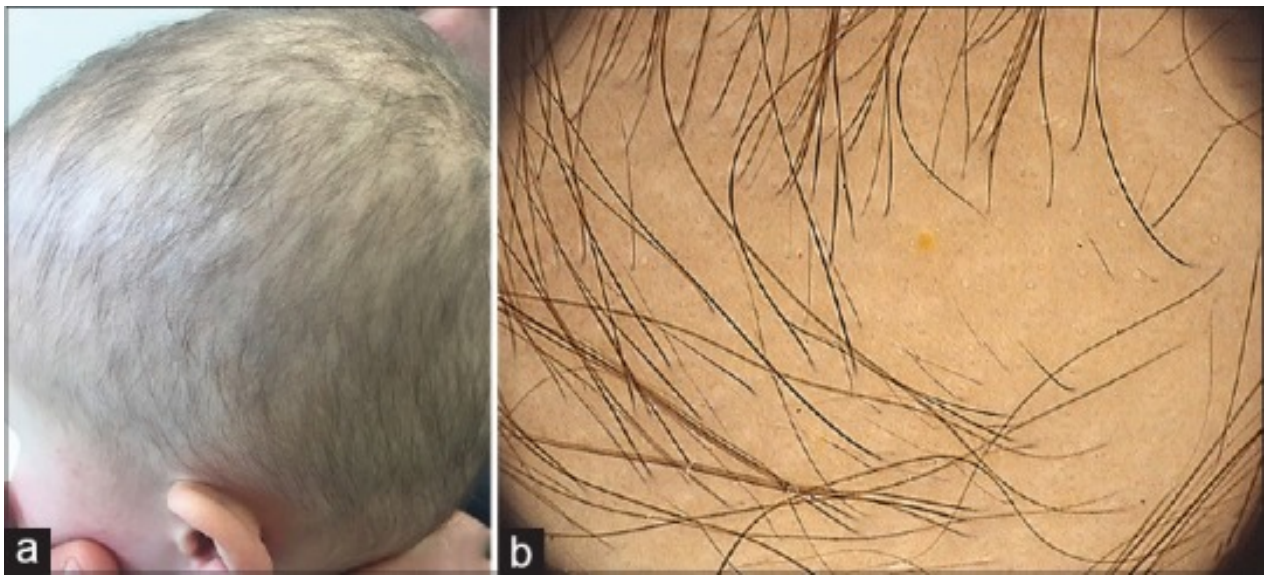

(a) Short sparse scalp hair, fine in texture, with low overall density. (b) Trichoscopy showing short, thin and vellus hairs and a yellow dot 


\section{Figure 2}

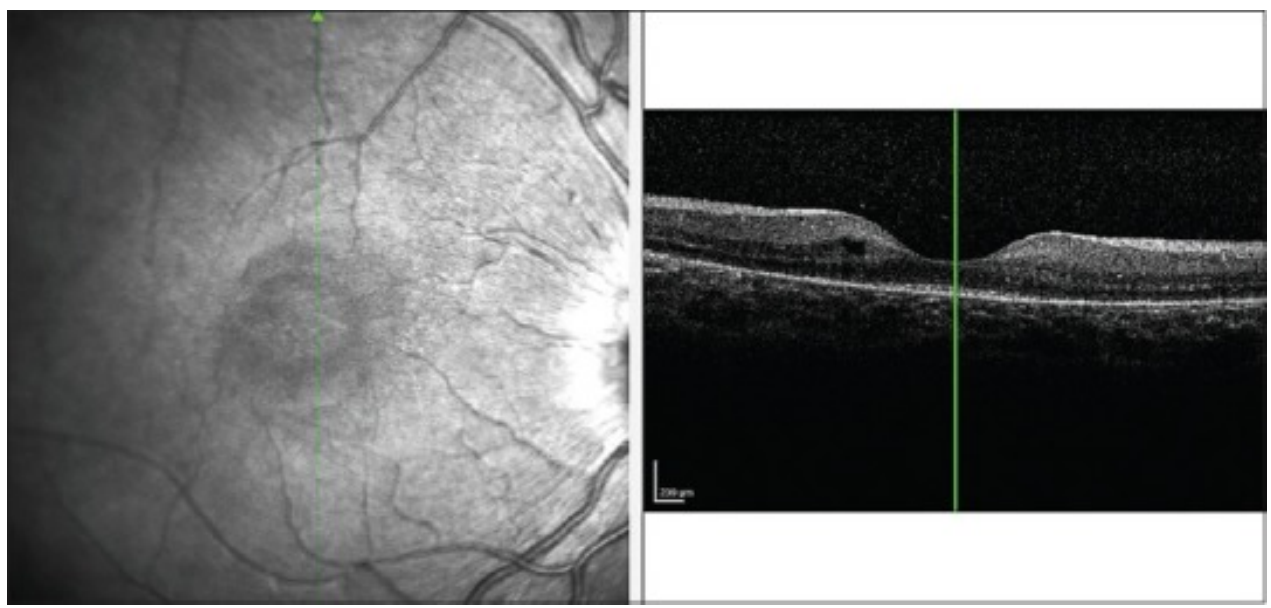

Optical coherence tomography showing irregularity of the photoreceptor layer and intraretinal cysts

Articles from International Journal of Trichology are provided here courtesy of Wolters Kluwer -- Medknow Publications 